This is a self-archived version of an original article. This version may differ from the original in pagination and typographic details.

Author(s): Kortet, Sami; Claraz, Aurélie; Pihko, Petri M.

Title: Catalytic Enantioselective Total Synthesis of (+)-Lycoperdic Acid

Year: 2020

Version: Accepted version (Final draft)

Copyright: @ 2020 American Chemical Society

Rights: In Copyright

Rights url: http://rightsstatements.org/page/lnC/1.0/?language=en

Please cite the original version:

Kortet, S., Claraz, A., \& Pihko, P. M. (2020). Catalytic Enantioselective Total Synthesis of (+)-Lycoperdic Acid. Organic Letters, 22(8), 3010-3013.

https://doi.org/10.1021/acs.orglett.0c00772 


\title{
Catalytic Enantioselective Total Synthesis of (+)-Lycoperdic Acid
}

\author{
Sami Kortet, Aurélie Claraz and Petri M. Pihko* \\ Department of Chemistry and NanoScience Center, University of Jyväskylä, Survontie 9B, 40520 Jyväskylä, Finland
}

Supporting Information Placeholder

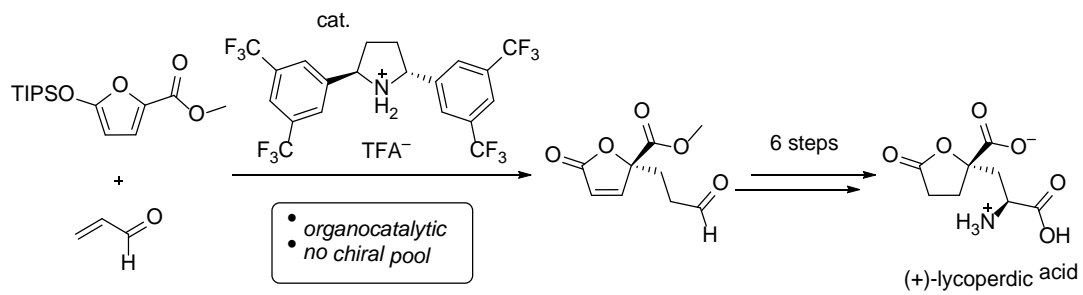

ABSTRACT: A concise enantio- and stereocontrolled synthesis of (+)-lycoperdic acid is presented. The stereochemical control is based on iminium-catalyzed Mukaiyama-Michael reaction and enamine-catalyzed organocatalytic $\alpha$-chlorination steps. The amino group was then introduced by azide displacement, affording the final stereochemistry of (+)-lycoperdic acid. Penultimate hydrogenation and saponification afforded pure (+)-lycoperdic acid in seven steps from a known silyloxyfuran.

(+)-Lycoperdic acid (1) was isolated from a mushroom Lycoperdon perlatum by Rhugenda-Banga et al. ${ }^{1}$ It is an amino acid that shares structural similarities with both L-glutamic acid (2) and dysiherbaines (3a, 3b, Figure 1). ${ }^{2,3}$ The dysiherbaines are well-known ionotropic glutamate receptor binders ${ }^{3,4}$, a fact which has raised questions about the biological activity of (+)1 over the years. ${ }^{5-7}$

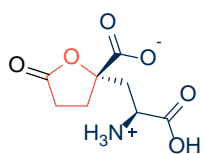

(+)-lycoperdic acid (1)<smiles>[R]C1[C@H](O)CO[C@H]2C[C@](C[C@H]([NH3+])C(=O)O[Na])(C(=O)[O-])O[C@H]12</smiles>

$$
\begin{array}{ll}
\text { ( )-neodysiherbaine } A \text { : } \\
/ \mathrm{OH} & \mathrm{R}=\mathrm{OH}(\mathbf{b})
\end{array}
$$

Figure 1. Glutamate-Related Amino Acids

To date, there are seven total syntheses and one formal synthesis for (+)-1. ${ }^{5-14}$ Most of them rely on either chiral pool or chiral auxiliaries to set the stereochemistry at C2 and C4 (Figure 2). Very recently, the Oikawa group disclosed an approach where catalytic enantioselective hydrogenation was used to control the stereochemistry at C2 of $(+)-\mathbf{1}$, but the construction of C4 was not stereoselective. ${ }^{7}$

Herein, a total synthesis for $(+)-\mathbf{1}$ is presented where the stereochemistry is fully controlled by organocatalytic reactions. Retrosynthetically, the C2 stereocenter was envisioned to be set via $\alpha$-amination reaction (Scheme 1). ${ }^{15,16}$ The challenging C4 tertiary stereogenic center would be accessed via a Mukaiyama-Michael reaction between a silyloxyfuran $\mathbf{4}$ and acrolein (6). ${ }^{17}$

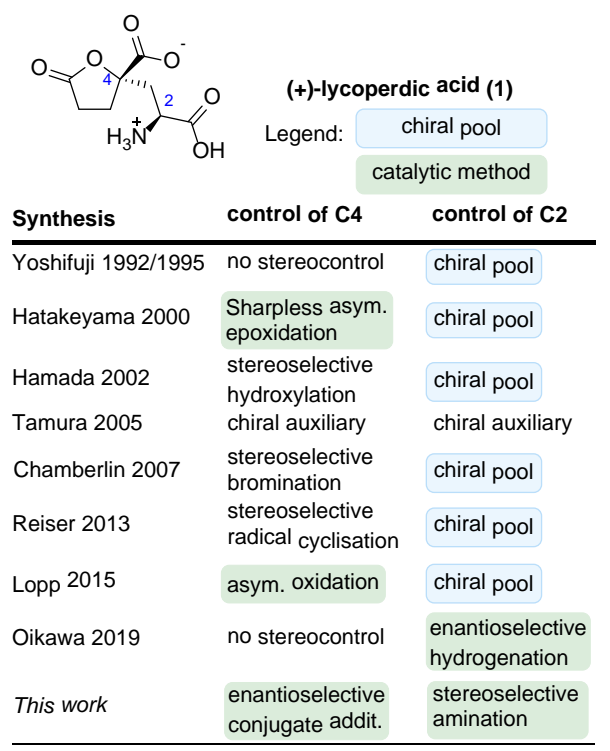

Figure 2. Sources of stereochemistry in the published routes

Our first challenge was to find the conditions for the desired Mukaiyama-Michael reaction with silyloxyfuran esters such as 4. The closest precedent was set by Pansare group who demonstrated that MacMillan's trimethyl imidazolidinone 5 would catalyse reactions between acrolein and silyloxyfurans with good enantioselectivities but with poor yields (Scheme 1). ${ }^{18}$ Our own previous experience with enantioselective MukaiyamaMichael reactions with acrolein involving diphenylpyrrolidine (9) ${ }^{19}$ and pyroglutamic-acid-derived pyrrolidine ${ }^{20}$ catalysts suggested that systematic optimization of the catalyst might offer better results.

In contrast with the Pansare precedent, we wanted to avoid the use of any bulky ester groups, or even benzyl esters in the 
nucleophilic component to prevent any conflict with later operations along the route (Scheme 1). For example, benzyl esters were deemed unsuitable as they might require special precautions in the projected hydrogenation of the butenolide $\mathrm{C}=\mathrm{C}$ bond. We thus selected the methyl ester $\mathbf{4}$ as the starting point for catalyst development.

\section{Scheme 1. Background of the study}

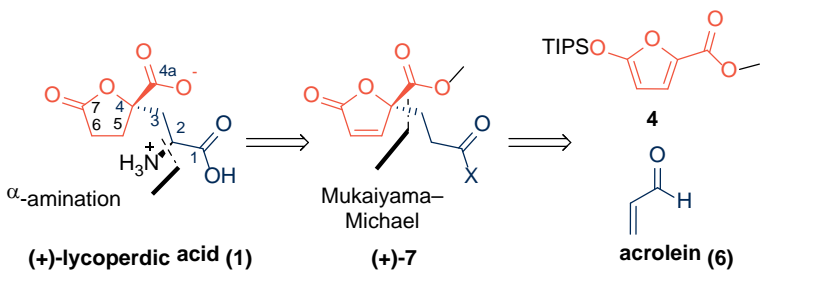

\section{Precédénts:}

- Problems with yield and selectivity (Pansare and co-workers, 2010)

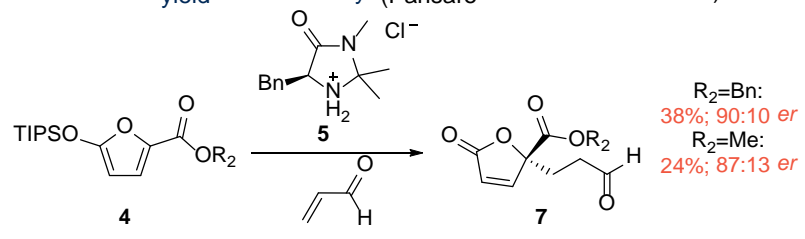

- The starting material is not functionalized (Pihko and co-workers, 2012)

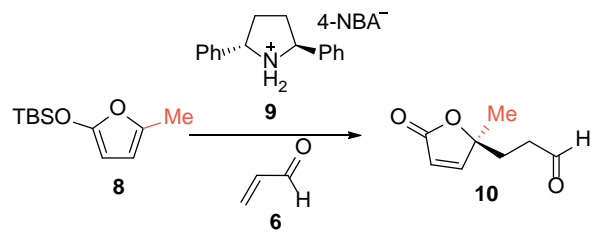

$65 \% ; 97: 3$ er

Hypothesis: optimized catalyst should give better yield/selectivity towards 7

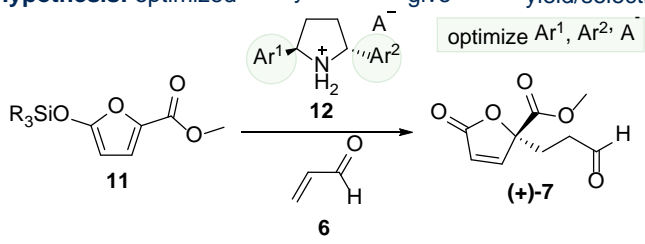

The work commenced by screening studies with typical iminium catalysts $\mathbf{9}$ and 13-15 (Scheme 2). These catalysts, unfortunately, gave only poor to moderate enantiomeric ratios. Nevertheless, comparison of differently substituted catalysts revealed potentially useful trends. Thus, catalysts with electron withdrawing substituents enhanced the enantioselectivities: with para-substituted diarylpyrrolidine catalysts, there was a rising trend from $\mathrm{F}$ (er 80:20, 16) via $\mathrm{NO}_{2}\left(\right.$ er 18:82, 17) to $\mathrm{CF}_{3}$ (er 85:15, 18). In contrast, electron-donating groups $(t-\mathrm{Bu})$ had a detrimental effect on er (catalyst S37, 57:43 er, see the Supporting Information, Scheme S1). Interestingly, catalysts 18 and 19, bearing either $p-\mathrm{CF}_{3}(\mathbf{1 8})$ or two $m-\mathrm{CF}_{3}$ groups $(\mathbf{1 9})$ afforded similar enantioselectivities. Finally, diarylpyrrolidine 20 with four $\mathrm{CF}_{3}$-substituents provided a reaction with excellent level of enantioselectivity.

Studies to further enhance the er of the reaction were also carried out. For further optimization, it was clear that the diarylpyrrolidine core of catalysts 16-20 was lacking the needed modularity. Thus, we also screened with pyroglutamic-acid-derived pyrrolidine catalysts and the above trend was also observed with these catalysts (Scheme 2). Catalyst $\mathbf{2 1}$ gave almost a racemic product, along with a group of catalysts with electron donating substituents (see Supporting information, Scheme S1) but addition of electron-withdrawing $\mathrm{CF}_{3}$-groups improved the er of the reaction from 68:32 to 89:11 (catalysts 22 and 23). Unfortunately, the change of the phenyl-substituent of 23 to a 3,5-bis- $\mathrm{CF}_{3}$-phenyl (catalyst 24) or a pentafluorophenyl-substituent (catalyst 25) failed to elicit higher enantioselectivities. With these results, we decided to proceed with the total synthesis with our most selective catalyst 20.

Scheme 2. Screening the catalysts for the Mukaiyama-Michael reaction ${ }^{\mathrm{a}}$
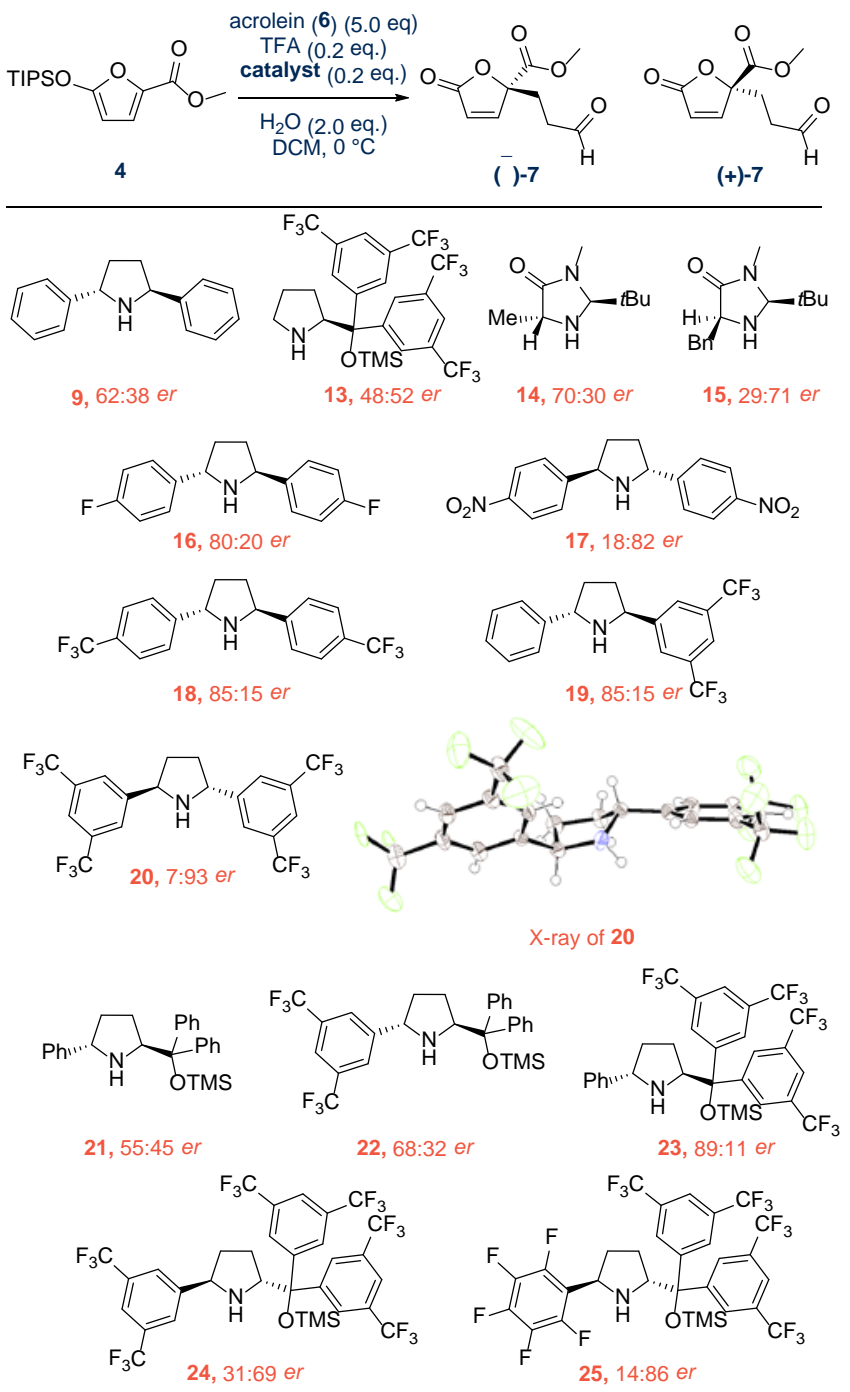

a) Enantiomeric ratios determined by chiral GC from the reaction mixture.

Further optimization of the reaction conditions (Table S1, entry 7, Supporting Information) revealed that TFA was the optimal counteracid. Lowering the temperature to $-30{ }^{\circ} \mathrm{C}$ had no effect on er but the conversion fell dramatically. Interestingly, when water was excluded from the reaction, er of 95:5 was achieved (Table S1, entries 10 and 11, Supporting information). Unfortunately, the reaction never reached completion, thus making these conditions unpractical. ${ }^{21}$

With these conditions at hand, we continued with the total synthesis. The entire route is shown in Scheme 3 starting from 
the known silyloxyfuran 4 (see also the Supporting Information). ${ }^{22,23}$ In gram-scale, the enantioselective MukaiyamaMichael reaction afforded the aldehyde $(+)-7$ in $47 \%$ yield and er 94:6. (+)-7 was then reduced to 27 with an $86 \%$ yield after chromatographic purification. In both of these transformations, the sensitivity of acrolein, $(+)-\mathbf{7}$ or $\mathbf{2 7}$ to polymerization were found to hamper the yields.

In our initial route, aldehyde 27 was first $\alpha$-aminated with DBAD (28) using List's protocol ${ }^{16}$, and the resulting amino aldehyde 29 was oxidised to the corresponding carboxylic acid 30. Unfortunately, this relatively straightforward route to (+)lycoperdic acid had to be abandoned since the subsequent $\mathrm{N}-$ N-bond cleavage could not be reliably achieved (Scheme 3). ${ }^{24}$

In the alternative, ultimately successful route (Scheme 3), aldehyde 27 was subjected to an organocatalytic $\alpha$-chlorination reaction, using perchlorinated quinone 31 as the $\mathrm{Cl}^{+}$-source and the MacMillan imidazolidinone TFA-salt $\mathbf{1 4}$ as the catalyst. ${ }^{25,26}$ Instead of 31, $N$-chlorosuccinimide was also tested in this reaction, but it afforded lower conversions than quinone $31 .{ }^{27}$ The intermediate $\alpha$-chloroaldehyde was directly oxidised in the same pot to the corresponding carboxylic acid 32. ${ }^{28}$ The crude acid was then methylated with $\mathrm{MeI}$ under basic conditions, yielding the diester $\mathbf{3 3}$ in $\mathbf{7 1 \%}$ yield over two steps. It was noteworthy that this two-step sequence could not be carried out with unsaturated aldehyde $(+)-7$; a complex mixture of compounds was obtained under the same reaction conditions. The diester $\mathbf{3 3}$ was then converted into the corresponding azide via $\mathrm{S}_{\mathrm{N}} 2-$ reaction with $\mathrm{NaN}_{3}$, yielding the azide 34 in $84 \%$ yield. The azide group was then converted to the Boc-protected amino group via hydrogenolysis in the presence of $\mathrm{Boc}_{2} \mathrm{O}$. To our delight, the diastereomers were separable chromatographically at this stage, giving the desired full-protected natural product 35 in $74 \%$ yield, alongside with 4-epi-35 (9\%, 86:14 diastereomeric purity).

With diastereomerically pure 35, the final stages were then explored. Saponification under basic conditions led to epimerization of the labile $\mathrm{C} 2$ stereocenter. In contrast, refluxing the compound 35 in $6 \mathrm{M} \mathrm{HCl}$ smoothly removed the Boc- and ester protecting groups, and after neutralization of the hydrochloride salt by an ion exchange column, crude $(+)-\mathbf{1}$ was in our hands. In order to get analytically pure samples and to remove the hydroxy acid 36, the crude product was recrystallized twice from water giving us pure (+)-1 in $28 \%$ yield. It was noteworthy that $\mathbf{3 6}$ could not be transformed to the lactone by dehydration (e.g. benzene, reflux) since these conditions resulted in the formation of several side products.
Scheme 3. The total synthesis route.
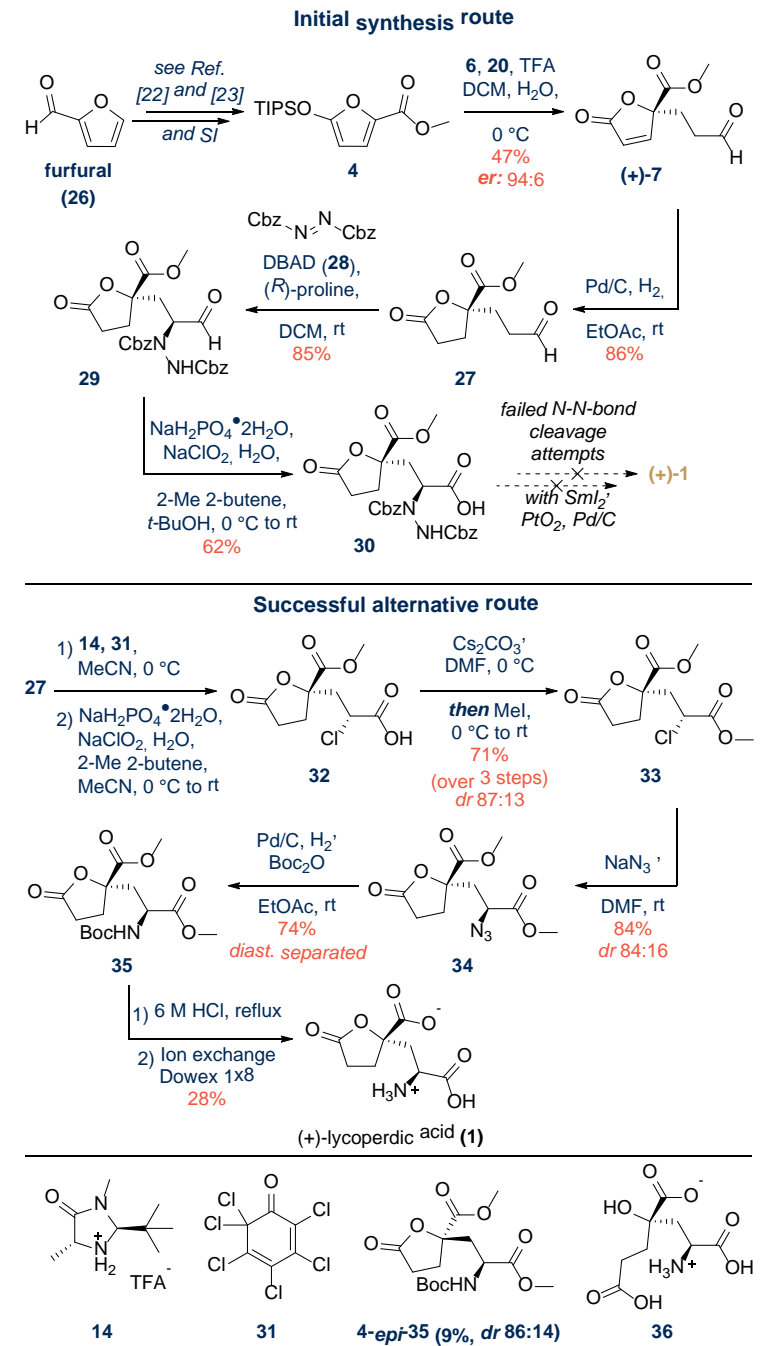

In summary, we have developed an enantioselective organocatalytic total synthesis route for $(+)$-lycoperdic acid without using a chiral pool approach. As the key transformation, iminium-catalysed Mukaiyama-Michael reaction between silyloxyfuran 4 and acrolein (6) using a specifically optimized catalyst 20 successfully installed the key C4 tertiary stereogenic center. Efforts to synthesise derivatives of $(+)-\mathbf{1}$ as well as wider studies of the developed Mukaiyama-Michael reaction are on their way.

\section{ASSOCIATED CONTENT}

\section{Supporting Information}

Experimental details, characterisation data and copies of ${ }^{1} \mathrm{H}$ and ${ }^{13} \mathrm{C}$ NMR spectra (PDF) are available free of charge on the ACS Publications website. Crystallographic data was deposited with the accession number 1972521, and can be obtained free of charge from The Cambridge Crystallographic Data Centre via www.ccdc.cam.ac.uk/structures.

\section{AUTHOR INFORMATION}

\section{Corresponding Author}

* e-mail: petri.pihko@jyu.fi 


\section{Notes}

The authors declare no competing financial interest.

\section{ACKNOWLEDGMENT}

Financial support from the Academy of Finland (projects \#259532, 297874,307624 ) is gratefully acknowledged. S.K. thanks the Graduate School of Chemistry for financial support, Prof. Kari Rissanen (JYU), Dr. Rakesh Puttreddy (JYU) and Dr. Arto Valkonen (JYU) for the valuable teaching and discussions on single-crystal $\mathrm{X}$-ray measurements. We thank Dr. Gokarneswar Sahoo (JYU) and Roosa-Maria Willman (JYU) for the valuable work with the catalysts, Johanna Hiidenheimo (JYU) for assistance with the HRMS and Esa Haapaniemi (JYU) for assistance with the NMR.

\section{REFERENCES}

(1) Rhugenda-Banga, N.; Welter, A.; Jadot, J.; Casimir, J. Un Nouvel Acide Amine Isole de Lycoperdon Perlatum. Phytochemistry 1979, 18 (3), 482-484.

(2) Sakai, R.; Kamiya, H.; Murata, M. Dysiherbaine: A New Neurotoxic Amino Acid From a Micronesian Marine Sponge Dysidea Herbacea. Symp. Chem. Nat. Prod. 1996, No. 38, 463468.

(3) Sakai, R.; Koike, T.; Sasaki, M.; Shimamoto, K.; Oiwa, C.; Yano, A.; Suzuki, K.; Tachibana, K.; Kamiya, H. Isolation, Structure Determination, and Synthesis of Neodysiherbaine A, a New Excitatory Amino Acid from a Marine Sponge. Org. Lett. 2001, 3 (10), 1479-1482.

(4) Sakai, R.; Kamiya, H.; Murata, M.; Shimamoto, K. Dysiherbaine: A New Neurotoxic Amino Acid from the Micronesian Marine Sponge Dysidea Herbacea. J. Am. Chem. Soc. 1997, 119 (18), 4112-4116.

(5) Yoshifuji, S.; Kaname, M. Asymmetric Synthesis of Lycoperdic Acid. Chem. Pharm. Bull. (Tokyo). 1995, 43, 1617-1620.

(6) Cohen, J. L.; Chamberlin, A. R. Diastereoselective Synthesis of Glutamate-Appended Oxolane Rings: Synthesis of (S)-(+)Lycoperdic Acid. J. Org. Chem. 2007, 72 (24), 9240-9247.

(7) Morokuma, K.; Irie, R.; Oikawa, M. Total Synthesis of Lycoperdic Acid and Its C4-Epimer. Tetrahedron Lett. 2019, 60 (31), 2067-2069.

(8) Kaname, M.; Yoshifuji, S. First Synthesis of Lycoperdic Acid. Tetrahedron Lett. 1992, 33 (52), 8103-8104.

(9) Masaki, H.; Mizozoe, T.; Esumi, T.; Iwabuchi, Y.; Hatakeyama, S. Stereocontrolled Synthesis of (+)-Lycoperdic Acid Based on a Palladium Catalyzed Reaction Using a Serine-Derived Organozinc Reagent. Tetrahedron Lett. 2000, 41, 4801-4804.

(10) Makino, K.; Shintani, K.; Yamatake, T.; Hara, O.; Hatano, K.; Hamada, Y. Stereoselective Synthesis of (S)-(+)-Lycoperdic Acid through an Endo Selective Hydroxylation of the Chiral Bicyclic Lactam Enolate with MoOPH. Tetrahedron 2002, 58 (48), 9737-9740.

(11) Tamura, O.; Shiro, T.; Ogasawara, M.; Toyao, A.; Ishibashi, H. Stereoselective Syntheses of 4-Hydroxy 4-Substituted Glutamic Acids. J. Org. Chem. 2005, 70 (12), 4569-4577.

(12) Kachkovskyi, G.; Faderl, C.; Reiser, O. Visible Light-Mediated Synthesis of (Spiro)Anellated Furans. Adv. Synth. Catal. 2013, 355 (11-12), 2240-2248.

(13) Paju, A.; Kostomarova, D.; Matkevitš, K.; Laos, M.; Pehk, T.; Kanger, T.; Lopp, M. 3-Alkyl-1,2-Cyclopentanediones by Negishi Cross-Coupling of a 3-Bromo-1,2-Cyclopentanedione Silyl Enol Ether with Alkylzinc Reagents: An Approach to 2Substituted Carboxylic Acid Gamma-Lactones, Homocitric and Lycoperdic Acids. Tetrahedron 2015, 71 (49), 9313-9320.

(14) Denton, R. W.; Kempf, A.; Singh, J.; C. Merrer, D. A Facile Synthesis of 4-Substituted Glutamate Derivative via 1,3-Dipolar Cycloaddition of Dimethyl 2- Methyleneglutarate and Nitrone Derived (-)-Menthone. Heterocycles 2020, 100 (2), 1877.

(15) Halland, N.; Braunton, A.; Bachmann, S.; Marigo, M.; Jørgensen, K. A. Direct Organocatalytic Asymmetric $\alpha$-Chlorination of Aldehydes. J. Am. Chem. Soc. 2004, 126 (15), 4790-4791.

(16) List, B. Direct Catalytic Asymmetric $\alpha$-Amination of Aldehydes.
J. Am. Chem. Soc. 2002, 124 (20), 5656-5657.

Brown, S. P.; Goodwin, N. C.; MacMillan, D. W. C. The First Enantioselective Organocatalytic Mukaiyama-Michael Reaction: A Direct Method for the Synthesis of Enantioenriched $\gamma$ Butenolide Architecture. J. Am. Chem. Soc. 2003, 125 (5), 11921194.

(18) Pansare, S. V.; Adsool, S. V.; Dyapa, R. Enantioselective Synthesis of (S)-Homocitric Acid Lactone and $(R)$-perHomocitric Acid Lactone Involving Organocatalysis. Tetrahedron Asymmetry 2010, 21 (7), 771-773.

(19) Kemppainen, E. K.; Sahoo, G.; Valkonen, A.; Pihko, P. M. Mukaiyama-Michael Reactions with Acrolein and Methacrolein: A Catalytic Enantioselective Synthesis of the C17-C28 Fragment of Pectenotoxins. Org. Lett. 2012, 14, 1086-1089.

(20) Claraz, A.; Sahoo, G.; Berta, D.; Madarász, Á.; Pápai, I.; Pihko, P. M. A Catalyst Designed for the Enantioselective Construction of Methyl- and Alkyl-Substituted Tertiary Stereocenters. Angew. Chemie - Int. Ed. 2016, 55 (2), 669-673.

(21) The reason for the loss of catalytic activity at cold temperatures is not known. However, we note that MacMillan and co-workers never used temperatures lower than $-20^{\circ} \mathrm{C}$ with TIPS-protected silyloxyfurans, while lower temperatures (down to $-70^{\circ} \mathrm{C}$ ) were used with TMS ethers (see Ref 17, Tables 1-3 and Scheme 3). At this point, we can only speculate that the slower hydrolysis of TIPS ether shuts down the catalytic cycle at low temperatures.

(22) Näsman, J. H. 3-Methyl-2(5H)-Furanone. Org. Synth. 1990, 68, 162.

(23) Naito, S.; Escobar, M.; Kym, P. R.; Liras, S.; Martin, S. F. Novel Approach to the Zaragozic Acids. Enantioselective Total Synthesis of 6,7-Dideoxysqualestatin H5. J. Org. Chem. 2002, 67 (3), 4200-4208.

(24) Hydrogenolysis attempts with $\mathrm{Pd} / \mathrm{C}$ and $\mathrm{PtO}_{2}$ gave complex reaction mixtures as well as reductive cleavage attempts with $\mathrm{SmI}_{2}$ with the Barbas method: Suri, J. T.; Steiner, D. D.; Barbas, C. F. Organocatalytic Enantioselective Synthesis of Metabotropic Glutamate Receptor Ligands. Org. Lett. 2005, 7 (18), 3885-3888. Brochu, M. P.; Brown, S. P.; MacMillan, D. W. C. Direct and Enantioselective Organocatalytic $\alpha$-Chlorination of Aldehydes. $J$. Am. Chem. Soc. 2004, 126 (13), 4108-4109.

(26) Kaplaneris, N.; Spyropoulos, C.; Kokotou, M. G.; Kokotos, C. G. Enantioselective Organocatalytic Synthesis of 2-Oxopiperazines from Aldehydes: Identification of the Elusive Epoxy Lactone Intermediate. Org. Lett. 2016, 18 (22), 5800-5803.

(27) Christmann and co-workers have explored the possible problems related to the reaction with NCS, which most probably were also present in our attempts: Ponath, S.; Menger, M.; Grothues, L.; Weber, M.; Lentz, D.; Strohmann, C.; Christmann, M. Mechanistic Studies on the Organocatalytic $\alpha$-Chlorination of Aldehydes: The Role and Nature of Off-Cycle Intermediates. Angew. Chemie - Int. Ed. 2018, 57 (36), 11683-11687.

(28) Chromatographic purification of the intermediate chloroaldehyde should be avoided to prevent possible epimerisation and side product formation. 